\title{
REVIEW QUESTIONS
}

1. This procedure is not for all concrete. Under what concrete conditions would this procedure not be used?

2. Describe the mold used for making the slump test.

3. The surface on which the slump cone will be placed must be

4. The approximate concrete depth (in vertical distance) after placing the first layer is and the second layer is

5. When rodding the bottom layer, the tamping rod must be to uniformly distribute the strokes.

6. If, while rodding the top layer, the concrete drops below the top of the slump cone, what must be done?

7. The measurement for slump is made from the top of the mold to what point of the concrete specimen?

8. While the technician is checking the slump of the concrete, there is a decided falling away or shearing off of concrete from one side of the sample. What should the technician do? 